\title{
PRIMATE SONGS AND THEIR RELEVANCE IN THE STUDY OF LANGUAGE EVOLUTION
}

\author{
MARCO GAMBA $^{* 1}$, VALERIA TORTI ${ }^{1}$, LONGONDRAZA MIARETSOA ${ }^{1}$, DARIA \\ VALENTE $^{1}$, CHIARA DE GREGORIO ${ }^{1}$, MARTINA TUBITO ${ }^{2}$, MARTINA \\ ZARANTONELLO $^{1}$, VITTORIO L. BIANCO ${ }^{1}$, LIVIO FAVARO ${ }^{1}$, OLIVIER \\ FRIARD $^{1}$, and CRISTINA GIACOMA ${ }^{1}$, \\ *Corresponding Author: marco.gamba@unito.it \\ ${ }^{1}$ Department of Life Sciences and Systems Biology, University of Torino, Torino, Italy \\ ${ }^{2}$ Zoom Torino Spa, Cumiana (To), Italy
}

It has been suggested that early human vocal communication should result from at least two critical abilities: the ability to engage in cooperative efforts (Levinson, 2005), and the ability to combine sounds in larger structures (Collier et al., 2014). These characteristics are essential features of choral songs, and, in fact, Darwin speculated that language might have originated from singing. The rhythms and pitch contours that distinguish songs in other species may be investigated to understand the roots of our language. Many authors have indicated birds and singing primates as the natural target of these studies (Geissmann, 2000).

The evolution of songs in nonhuman primates has been associated with a monogamous mating system and to the active defense of a territory. We have investigated the layers of complexity of the songs emitted by three nonhuman primate species: the siamang (Symphalangus syndactylus), the white-handed gibbon (Hylobates lar), and the indri (Indri indri). Although the single species have received attention from scientists, a comparative approach investigating frequency variation and individual temporal patterns has never been used.

For each of these species, we analyzed songs from different social groups and hierarchically classified the units emitted in the songs in phrases using dynamic time warping and cluster analysis. For each unit, we extracted a pitch 
contour and labeled it by the context in which songs were emitted and by the sex of the emitter.

We found that a) primate songs show a species-specific structure in the organization of units and phrases; b) a shared feature across the three species was the presence of an apparent sex dimorphism, and c) song given in different context (e.g., cohesion vs. advertisement) have distinctive acoustic structures. Moreover, we found that the structure of phrases possessed individually distinctive characteristics, thus the potential to provide conspecifics with emitter's identity cues.

These findings are relevant to the evolution of language for three reasons. Similarly to humans, siamangs, white-handed gibbons, and indris assemble simple units into more complex structures to convey different information, and individuals react differently to different songs, confirming the presence of functionally referential communication systems and a simple phonological syntax in nonhuman primates (Marler, 1977). The songs reach their most consistent portions in ascending or descending sequences of units, which indeed represent an interesting case of timing and pitch variation, a crucial feature of birdsong and human speech (Levinson and Holler, 2014). The presence of pitch sex dimorphism in nonhuman primate vocal signals is rare, and it has been indicated as a critical element in the evolution of human perceptual abilities (Patel, 2010). Finally, portions of the song have the potential to provide information about the individual identity of the emitters, suggesting that the transmission of identity-related cues at long distance is a trait of the living singing primates may have in common with the first human societies (Brown, 2000).

The range of species capable of cooperative singing is very restricted, and further research is needed to find out whether the singing capacity is associated with other critical features of human communication and musicality that have rarely been found in nonhuman species (e.g., the capacity to synchronize with a beat). These future studies will contribute to the identification of which aspects of our nonverbal auditory processing are shared with other species, and which are indeed uniquely human.

\section{References}

Brown, S. (2000). The "musilanguage" model of music evolution. In N.L. Wallin, B. Merker \& S. Brown (Eds.). The Origins of Music (pp. 271-300). Cambridge: MIT Press. 
Collier, K., Bickel, B., van Schaik, C. P., Manser, M. B., \& Townsend, S. W. (2014). Language evolution: syntax before phonology? Proceedings of the Royal Society B: Biological Sciences, 281, 20140263.

Geissmann, T. (2000). Gibbon songs and human music from an evolutionary perspective. In N.L. Wallin, B. Merker \& S. Brown (Eds.). The Origins of Music (pp. 103-123). Cambridge: MIT Press.

Levinson, S. C. (1995). Interactional biases in human thinking. In E. N. Goody (Ed.), Social Intelligence and Interaction (pp. 221-260). Cambridge: Cambridge University Press.

Levinson, S. C., and Holler, J. (2014). The origin of human multi-modal communication. Philosophical Transactions Royal Society London B: Biological Sciences, 369, 20130302.

Marler P (1977) The structure of animal communication sounds. In: Bullock TH (Ed.). Recognition of complex acoustic signals (pp. 17-35). Berlin: Springer.

Patel, A. D. (2010). Music, language, and the brain. Oxford: Oxford university press. 